Check for updates

Cite this: RSC Adv., 2017, 7, 29143

\title{
Selective hydrogenation of $p$-chloronitrobenzene over an Fe promoted Pt/AC catalyst
}

\author{
Hu Chen, Daiping He, (D) * Qingqing He, Ping Jiang, (D) Gongbing Zhou \\ and Wensheng Fu
}

Activated carbon supported Pt (Pt/AC) and Fe modified Pt (Pt-Fe/AC) catalysts have been investigated for selective hydrogenation of $p$-chloronitrobenzene to $p$-chloroaniline. It was found that the incorporation of an appropriate amount of $\mathrm{Fe}(4 \mathrm{wt} \%)$ resulted in a remarkable increase in activity and selectivity to $p$ chloroaniline, and the catalytic hydrodechlorination over the catalyst was fully suppressed at complete conversion of $p$-chloronitrobenzene. X-ray photoelectron spectroscopy (XPS) revealed the electron transfer from Pt nanoparticles to $\mathrm{Fe}_{2} \mathrm{O}_{3}$, leading to the electron-deficient state of the Pt nanoparticles in the present catalyst, which is responsible for improved performance of the Pt-Fe/AC catalyst for $p$ chloronitrobenzene hydrogenation to $p$-chloroaniline.

Received 26th April 2017

Accepted 28th May 2017

DOI: $10.1039 / \mathrm{c} 7 \mathrm{ra0} 4700 \mathrm{~b}$

rsc.li/rsc-advances

deactivation. ${ }^{14}$ In most cases, high selectivity is always achieved

\section{Introduction}

The reduction of chloronitrobenzenes to chloroanilines is significant in organic synthesis because the chloroanilines are the key intermediates of pharmaceuticals, polymers, pesticides, explosives, fibers, dyes and cosmetics. ${ }^{1}$ The traditional methods that use either the $\mathrm{Fe} / \mathrm{HCl}$ system (Bechamp reaction) or metal sulfides inevitably generate large amounts of waste, which requires costly and laborious separation and disposal. ${ }^{2}$ Synthesis of chloroanilines using catalytic hydrogenation starting with chloronitrobenzenes offers several advantages over chemical reduction, including cheap hydrogen, easy product separation and a nonpolluting process. A severe problem related to the catalytic hydrogenation has been the cooccurrence of the catalytic hydrodechlorination reaction of the substrates, ${ }^{3-5}$ which significantly limits the selectivity to chloroanilines and leads to a lot of wastes. Furthermore, hydrogen chloride produced from the hydrodechlorination is also corrosive to the reactor. It is highly desirable to develop heterogeneous catalysts that would ensure the selective reduction of the nitro groups while leave intact of the carbon-chlorine bond in the same molecule. Many efforts have been devoted to performing selective hydrogenation of chloronitrobenzenes to corresponding chloroanilines over a plentiful of metal catalysts, ${ }^{6-11}$ including Pt, Pd, Au, Ru, Ni and Ag. The gold catalyst offers the highest selectivity of chloroanilines for this hydrogenation, ${ }^{12,13}$ but platinum seems to be the best catalyst for minimizing dechlorination combined with a fast rate of reduction of the nitro group and being highly resistant to

Key Lab of Green Synthesis and Applications, College of Chemistry, Chongqing Normal University, Chongqing 401331, China. E-mail: hedaiping@126.com; Fax: +86-236536-2777; Tel: +86-23-6591-0309 at the expense of activity by introducing either transition-metal salts or additives that partly poison the active sites. ${ }^{15-17}$ The choice of components is critical in developing an efficient and viable catalyst, and due attention should be paid to the interaction between active metal and promoter, since the nature of this interaction plays an important role in shaping the activity, selectivity and stability of the catalyst. Mahata $\mathrm{N}$ et al. ${ }^{18}$ studied the influence of $\mathrm{Cu}$ on the catalytic properties of $\mathrm{Pt} / \mathrm{C}$ for the hydrogenation of chloronitrobenzenes. It is found that the strong interactions between $\mathrm{Pt}$ and $\mathrm{Cu}$ result in partial coverage of the Pt surface by $\mathrm{Cu}$. The superficial $\mathrm{Cu}$ species activate the $\mathrm{N}=\mathrm{O}$ bond of chloronitrobenzene and also inhibit the adsorption of the desired product chloroaniline. Thus, the bimetallic catalysts exhibited excellent performance in producing selectively chloroanilines ( $>99 \%)$ in comparison to the Pt/AC catalyst. Moreover, the high catalytic activity of the Pt nanoclusters was maintained.

In this paper, we report the promotional effect of $\mathrm{Fe}$ on the catalytic performance of $\mathrm{Pt} / \mathrm{C}$ catalyst. The possible function of $\mathrm{Fe}$ in Pt-Fe/AC catalysts is discussed on the basis of catalyst characterization and catalytic results.

\section{Experimental}

\subsection{Catalyst preparation}

An activated carbon (AC) sample was obtained from Chongqing Chuandong Chemical Company and was crushed into 220-250 mesh powder. It was washed with distilled water, then dried at $383 \mathrm{~K}$ overnight and calcined in flowing air at $523 \mathrm{~K}$ for $3 \mathrm{~h}$. The $\mathrm{Pt}-\mathrm{Fe} / \mathrm{AC}$ catalyst was prepared by a wet impregnation technique. Typically, $2.0 \mathrm{~g}$ of activated carbon with BET surface area of $411 \mathrm{~m}^{2} \mathrm{~g}^{-1}$ was added to $50 \mathrm{~mL}$ aqueous $\mathrm{Fe}\left(\mathrm{NO}_{3}\right)_{3}(0.03 \mathrm{~mol}$ 
$\left.\mathrm{L}^{-1}\right)$ and the suspension was stirred for $24 \mathrm{~h}$. Then, $1.58 \mathrm{~mL}$ aqueous $\mathrm{H}_{2} \mathrm{PtCl}_{6}\left(3.8 \times 10^{-3} \mathrm{~mol} \mathrm{~L}^{-1}\right)$ was added dropwise to the mixture for $24 \mathrm{~h}$ upon continuous stirring. The deposition of $\mathrm{Pt}$ and Fe nanoparticles from the aqueous solution occurred when a stoichiometric excess of aqueous $\mathrm{NaBH}_{4}\left(0.5 \mathrm{~mol} \mathrm{~L}^{-1}\right)$ was added dropwise to the mixture. Stirring was continued for a further $5 \mathrm{~h}$. The solids were filtered and washed thoroughly with distilled water until free of chloride ions. The obtained sample was dried at $383 \mathrm{~K}$ for $10 \mathrm{~h}$ and calcined in flowing air at different temperature for $5 \mathrm{~h}$. The platinum, iron in the catalyst was $0.29 \mathrm{wt} \%$ and $3.86 \mathrm{wt} \%$ according to ICP-AES analysis, respectively.

\subsection{Catalyst characterization}

The platinum and iron contents in the $0.3 \% \mathrm{Pt}-4 \% \mathrm{Fe} / \mathrm{AC}$ catalyst were analyzed by means of inductively coupled plasma-atomic emission spectroscopy (ICP-AES) after the sample was dissolved in aqua regia. X-ray powder diffraction (XRD) patterns were recorded on a Rigaku D/Max Ultima IV Xray diffractometer using $\mathrm{Cu} \mathrm{K} \alpha$ radiation with accelerating voltage of $40 \mathrm{kV}$ and current of $30 \mathrm{~mA}$. Transmission electron microscopy (TEM) measurement was performed on a JEOL JEM2000EX microscope operated at an accelerating voltage of 120 $\mathrm{kV}$. An energy-dispersive X-ray (EDX) spectroscopic detecting unit was used to collect the EDX spectra for elemental analysis. $\mathrm{X}$-ray photoelectron spectra (XPS) were obtained on an ESCALAB $250 \mathrm{X}$-ray photoelectron spectroscopy using $\mathrm{Mg}$ - $\mathrm{K} \alpha \mathrm{X}$-ray as the excitation source. XPS spectra were calibrated based on the graphite C 1s peak at $284.6 \mathrm{eV}$.

\subsection{Catalyst testing}

The catalytic hydrogenation was carried out with magnetic stirring $(900 \mathrm{rpm})$ in a $60 \mathrm{~mL}$ Teflon-lined stainless steel autoclave containing $1.0 \mathrm{~g}$ of $p$-chloronitrobenzene ( $p$-CNB) in 8.0 $\mathrm{mL}$ ethanol (solvent). The catalyst used in each run of the reaction was $20.0 \mathrm{mg}$. The reactor was flushed one time with $0.5 \mathrm{MPa} \mathrm{N}_{2}$ and then four times with $0.5 \mathrm{MPa} \mathrm{H}_{2}$ before it was pressurized to the desired $\mathrm{H}_{2}$ pressure and placed in a heat installation maintained at the reaction temperature. The reaction was stopped at a selected time by cooling the reactor in a ice water bath. The products were analyzed by GC (GC9890) with an SE-30 capillary column and an FID as detector, using $o^{-}$ xylene as an internal standard.

\section{Results and discussion}

\subsection{Catalyst characterization}

The XRD patterns of the AC support and $0.3 \% \mathrm{Pt}-4 \% \mathrm{Fe} / \mathrm{AC}$ catalyst are shown in Fig. 1 . The AC support shows the characteristic diffraction peaks of graphitized activated carbon at $2 \theta$ $=24.3^{\circ}, 35.4^{\circ}$ and $43.2^{\circ} .^{19}$ The minor peaks at $20.7^{\circ}, 26.5^{\circ}$, $39.4^{\circ}, 50.1^{\circ}$ and $68.1^{\circ}$ are attributed to the presence of trace quantity of silica. ${ }^{20}$ The XRD pattern of the $0.3 \% \mathrm{Pt}-4 \% \mathrm{Fe} / \mathrm{AC}$ catalyst is similar to that of the AC support as we can see from Fig. 1b. No characteristic diffraction peaks at $39.9^{\circ}, 46.4^{\circ}$, $67.5^{\circ}$ index to (111), (200), (220) planes of metallic $\mathrm{Pt}^{21}$ and $44.4^{\circ}$

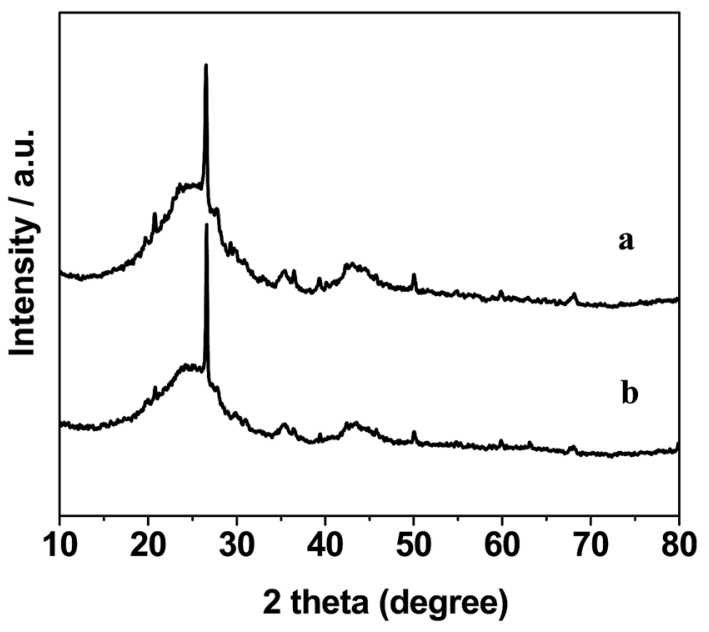

Fig. 1 XRD patterns of $A C(a)$ and $0.3 \% \mathrm{Pt}-4 \% \mathrm{Fe} / \mathrm{AC}(\mathrm{b})$.

assigned to $\mathrm{Fe}(110)$ plane $^{22}$ were detected in the $0.3 \% \mathrm{Pt}-4 \% \mathrm{Fe} /$ AC catalyst, probably because of the low percentage of metals on the catalyst and/or the small particle size.

Fig. 2 shows the representative TEM images of the $0.3 \% \mathrm{Pt}-$ $4 \% \mathrm{Fe} / \mathrm{AC}$ catalyst. As can be seen from the TEM image (Fig. 2a), small black spots can be discerned from the background over the $0.3 \% \mathrm{Pt}-4 \% \mathrm{Fe} / \mathrm{AC}$ catalyst. A combined EDX analysis showed that the signal of Pt and Fe could be detected in the small black spots (Fig. 2b). Therefore, we conclude that the small black spots in Fig. 2a are the images of the Pt and Fe species. The $\mathrm{Fe}$ and $\mathrm{Pt}$ particles in the $0.3 \% \mathrm{Pt}-4 \% \mathrm{Fe} / \mathrm{AC}$
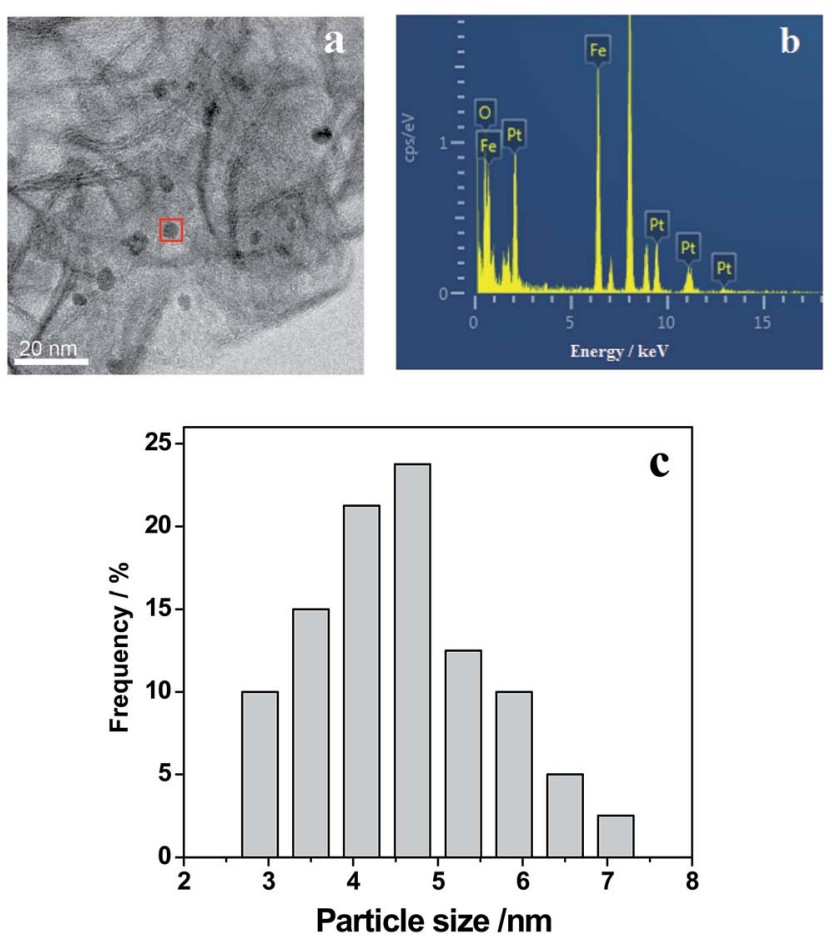

Fig. 2 TEM image of $0.3 \% \mathrm{Pt}-4 \% \mathrm{Fe} / \mathrm{AC}$ (a), EDX spectra of the selected area (b) and size distributions of Pt-Fe particles in the catalyst (c). 


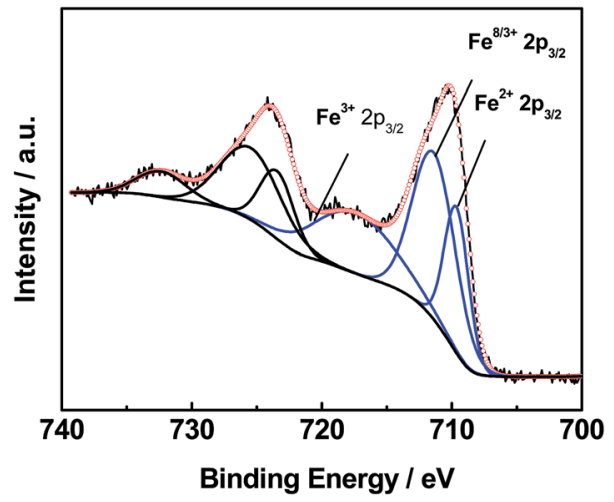

Fig. 3 XPS spectrum of $\mathrm{Fe} 2 \mathrm{p}_{3 / 2}$ for $0.3 \% \mathrm{Pt}-4 \% \mathrm{Fe} / \mathrm{AC}$.

catalyst have an average diameter of $4.5 \mathrm{~nm}$, with a size distribution from 3 to $7 \mathrm{~nm}$ (Fig. 2c), which is consistent with the absence of characteristic diffraction peaks of $\mathrm{Fe}$ and $\mathrm{Pt}$ in the XRD pattern of the $0.3 \% \mathrm{Pt}-4 \% \mathrm{Fe} / \mathrm{AC}$, suggesting that the $\mathrm{Fe}$ and $\mathrm{Pt}$ species on AC support are in a homogenous dispersion without any obvious aggregation.

XPS analyses of the $0.3 \% \mathrm{Pt} / \mathrm{AC}$ and $0.3 \% \mathrm{Pt}-4 \% \mathrm{Fe} / \mathrm{AC}$ catalysts were performed. The Fe $2 \mathrm{p}$ spectrum of the $0.3 \% \mathrm{Pt}-$ $4 \% \mathrm{Fe} / \mathrm{AC}$ can be deconvoluted three peaks (Fig. 3). The peaks can be assigned to $\mathrm{Fe}^{3+}$ in $\mathrm{Fe}_{2} \mathrm{O}_{3}, \mathrm{Fe}^{8 / 3+}$ in $\mathrm{Fe}_{3} \mathrm{O}_{4}$ and $\mathrm{Fe}^{2+}$ in $\mathrm{FeO}$, respectively. ${ }^{23}$ It is evident that the calcination of the $0.3 \% \mathrm{Pt}-$ $4 \% \mathrm{Fe} / \mathrm{AC}$ at $473 \mathrm{~K}$ in air leads to the formation of $\mathrm{Fe}_{2} \mathrm{O}_{3}$ on AC. Fig. 4 presents the $\mathrm{Pt} 4 \mathrm{f}$ spectra of the $0.3 \% \mathrm{Pt} / \mathrm{AC}$ and $0.3 \% \mathrm{Pt}-$ $4 \% \mathrm{Fe} / \mathrm{AC}$ catalysts. The $\mathrm{Pt} 4 \mathrm{f}_{7 / 2}$ photoelectron peak of the $0.3 \%$ $\mathrm{Pt} / \mathrm{AC}$ catalyst is observed at $71.2 \mathrm{eV}$ (Fig. 4a), which is consistent with the characteristic peak of $\mathrm{Pt} 4 \mathrm{f}_{7 / 2}$ for metallic Pt at $71.1 \mathrm{eV} .{ }^{24}$ However, the binding energy of the $\mathrm{Pt} 4 \mathrm{f}_{7 / 2}$ level in the $0.3 \% \mathrm{Pt}-4 \% \mathrm{Fe} / \mathrm{AC}$ catalyst (Fig. $4 \mathrm{~b}$ ) is $0.9 \mathrm{eV}$ higher than that of metallic Pt. This reveals the electron transfer and the electrondeficient state of the Pt nanoparticles in the $0.3 \% \mathrm{Pt}-4 \% \mathrm{Fe} /$ AC catalyst. Wang et al. ${ }^{25}$ also observed the same phenomenon in the $\mathrm{Pt} / \gamma-\mathrm{Fe}_{2} \mathrm{O}_{3}$ catalyst. Based on these results, we believe that the electron transfer may occur from the Pt particles to the $\mathrm{Fe}_{2} \mathrm{O}_{3}$ in the $0.3 \% \mathrm{Pt}-4 \% \mathrm{Fe} / \mathrm{AC}$ catalyst.

\subsection{Catalytic performance}

Table 1 shows the catalytic properties of the $4 \% \mathrm{Fe} / \mathrm{AC}, 0.3 \% \mathrm{Pt} /$ $\mathrm{AC}$ and $0.3 \% \mathrm{Pt}-\mathrm{Fe} / \mathrm{AC}$ catalysts for hydrogenation of $p$-CNB at $303 \mathrm{~K}, 1.0 \mathrm{MPa}_{2}$. No reaction of $p$-CNB was observed in the absence of the catalyst and over the $4 \% \mathrm{Fe} / \mathrm{AC}$ catalyst. The conversion of $p$-CNB over the $0.3 \% \mathrm{Pt} / \mathrm{AC}$ catalyst was $37 \%$ for 40 minutes. When the same $0.3 \% \mathrm{Pt} / \mathrm{AC}$ was loaded with $4 \% \mathrm{Fe}$, however, a dramatically high $p$-CNB conversion (65\%) was achieved under the same reaction conditions, and the selectivity to the desired product $p$-CAN also increased from $84.0 \%$ to $94.2 \%$, which may be attributed to $\mathrm{Fe}_{x} \mathrm{O}_{y}$ species activated the $\mathrm{N}=\mathrm{O}$ bond which becomes highly susceptible to hydrogen attack. ${ }^{26}$ When Fe loading amount further increases from $4 \mathrm{wt} \%$ to $6 \mathrm{wt} \%$, the conversion of $p$-CNB decreases from $65 \%$ to $33 \%$, which may be caused by partial coverage of the Pt surface by excess $\mathrm{Fe}_{x} \mathrm{O}_{y}$. Interestingly, the undesired hydrodechlorination

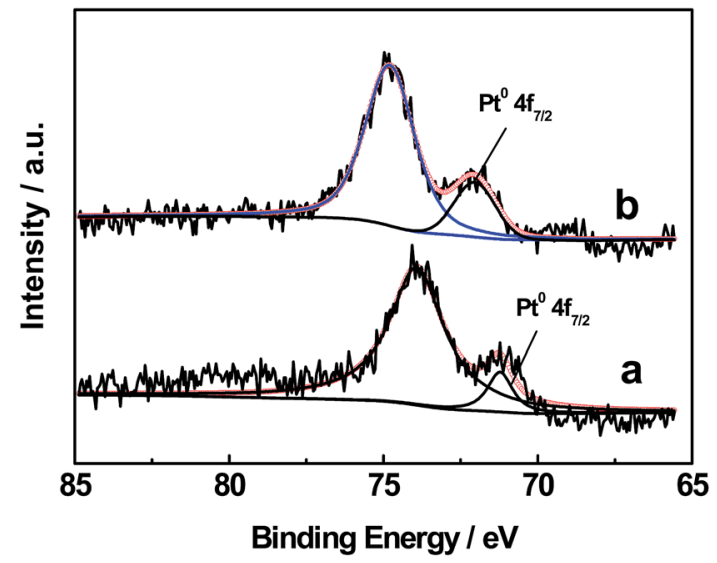

Fig. 4 XPS spectra of Pt $4 f_{5 / 2}$ for $0.3 \% \mathrm{Pt} / \mathrm{AC}(\mathrm{a})$ and $0.3 \% \mathrm{Pt}-4 \% \mathrm{Fe} /$ $A C(b)$.

reaction observed over the Pt/AC was not detected over the $0.3 \%$ $\mathrm{Pt}-4 \% \mathrm{Fe} / \mathrm{AC}$ catalyst. Special attention was paid to distinguish byproducts of the $p$-CNB hydrogenation reactions with GC-MS. Any byproduct that amounted to $0.1 \%$ in the reaction mixture can be unambiguously detected in our method of product analysis. We did not detect any by-products derived from the hydrodechlorination over the $0.3 \% \mathrm{Pt}-4 \% \mathrm{Fe} / \mathrm{AC}$ catalyst, even when the reaction time was extended by 30 minutes after $p$-CNB was exhausted, which indicates that the undesired hydrodechlorination reaction usually observed over other metal catalysts $^{27-29}$ can be successfully avoided over the catalyst. XPS data indicate that the electron transfer occurred from Pt to $\mathrm{Fe}_{2} \mathrm{O}_{3}$ make the Pt nanoparticles in the $0.3 \% \mathrm{Pt}-4 \% \mathrm{Fe} / \mathrm{AC}$ catalyst an electron-deficient state. The electron-deficient state of the Pt particles could weaken the extent of electron feedback from the Pt particles to the aromatic ring in chloroanilines and suppressed the hydrodechlorination reaction. ${ }^{25}$ Therefore, the high selectivity of $p$-CAN over the $0.3 \% \mathrm{Pt}-4 \% \mathrm{Fe} / \mathrm{AC}$ catalyst may attribute to the electron-deficient state of the $\mathrm{Pt}$ nanoparticles.

Table 1 Catalytic results of selective hydrogenation of $p$-CNB over different catalysts ${ }^{a}$

\begin{tabular}{lllll}
\hline & & \multicolumn{2}{l}{ Sel. $(\%)$} & \\
\cline { 5 - 5 } Catalyst & $(\mathrm{m}$-CNB $)$ & $p$-CAN & $\mathrm{AN}^{b}$ & Others $^{c}$ \\
\hline $4 \% \mathrm{Fe} / \mathrm{AC}$ & n.d. $(40)$ & n.d. & n.d. & n.d. \\
$0.3 \% \mathrm{Pt} / \mathrm{AC}$ & $37(40)$ & 84.0 & n.d. & 16.0 \\
$0.3 \% \mathrm{Pt}-2 \% \mathrm{Fe} / \mathrm{AC}$ & $50(40)$ & 92.6 & n.d. & 7.4 \\
$0.3 \% \mathrm{Pt}-4 \% \mathrm{Fe} / \mathrm{AC}$ & $65(40)$ & 94.2 & n.d. & 5.8 \\
$0.3 \% \mathrm{Pt}-4 \% \mathrm{Fe} / \mathrm{AC}$ & $100(90)$ & 100 & n.d. & n.d. \\
$0.3 \% \mathrm{Pt}-4 \% \mathrm{Fe} / \mathrm{AC}$ & $100(120)$ & 100 & n.d. & n.d. \\
$0.3 \% \mathrm{Pt}-6 \% \mathrm{Fe} / \mathrm{AC}$ & $33(40)$ & 92.7 & n.d. & 7.3
\end{tabular}

${ }^{a}$ n.d.: not detected. ${ }^{b}$ AN refers to aniline. ${ }^{c}$ Other products were $p$ chloronitrosobenzene, $4,4^{\prime}$-dichloroazoxybenzene and $4,4^{\prime}$ dichloroazobenzene. Reaction conditions: $20.0 \mathrm{mg}$ catalyst, $1.0 \mathrm{~g} p$ CNB in $8.0 \mathrm{~mL}$ ethanol (solvent), $303 \mathrm{~K}, 1.0 \mathrm{MPa} \mathrm{H}_{2}$. 
Table 2 Effect of calcination temperature on catalytic performance of $0.3 \% \mathrm{Pt}-4 \% \mathrm{Fe} / \mathrm{AC}$ for $p$-CNB hydrogenation

\begin{tabular}{lllll}
\hline & & \multicolumn{3}{l}{ Sel./\% } \\
\cline { 3 - 5 } Calci. temp./K & $p$-CNB conv./\% & $p$-CAN & AN $^{a}$ & Others $^{a}$ \\
\hline 383 & 33 & 91.4 & n.d. & 8.6 \\
473 & 65 & 94.2 & n.d. & 5.8 \\
573 & 57 & 93.8 & n.d. & 6.2 \\
623 & 51 & 93.2 & n.d. & 6.8
\end{tabular}

${ }^{a}$ See the note in Table 1. Reaction conditions are the same as in Table 1.

Table 3 Effect of reaction temperature on catalytic performance of $0.3 \% \mathrm{Pt}-4 \% \mathrm{Fe} / \mathrm{AC}$ for $p$-CNB hydrogenation

\begin{tabular}{lccll}
\hline & & \multicolumn{3}{l}{ Sel./\% } \\
\cline { 3 - 5 } React. temp./K & $p$-CNB conv./\% & $p$-CAN & $\mathrm{AN}^{a}$ & Others $^{a}$ \\
\hline 303 & 65 & 94.2 & n.d. & 5.8 \\
313 & 92 & 96.3 & n.d. & 3.7 \\
323 & 100 & 98.9 & n.d. & 1.1 \\
333 & 100 & 100 & n.d. & n.d.
\end{tabular}

${ }^{a}$ See the note in Table 1. Other reaction conditions are the same as in Table 1.

\subsection{Effect of calcination temperature}

The hydrogenation properties of the $0.3 \% \mathrm{Pt}-4 \% \mathrm{Fe} / \mathrm{AC}$ calcined at different temperature are also investigated, and the results are listed in Table 2. From Table 2, we can see that different calcination temperature of the $0.3 \% \mathrm{Pt}-4 \% \mathrm{Fe} / \mathrm{AC}$ has significant influence on the hydrogenation of $p$-CNB. The $0.3 \% \mathrm{Pt}-4 \% \mathrm{Fe} / \mathrm{AC}$ calcined at $473 \mathrm{~K}$ shows the best catalytic activity and selectivity towards $p$-CAN, which could can be the result of the favorable formation of $\mathrm{Fe}_{2} \mathrm{O}_{3}$ on $\mathrm{AC}$ at $473 \mathrm{~K}$, and the sintering of the Pt nanoparticles at higher calcination temperature $(>473 \mathrm{~K})$.

\subsection{Effect of reaction conditions}

The reaction temperature also plays a significant role in the $p$ CNB hydrogenation reaction (Table 3 ). The conversion of $p$-CNB and selectivity to $p$-CAN was $65 \%$ and $94.2 \%$ at $303 \mathrm{~K}$,

Table 4 Effect of $\mathrm{H}_{2}$ pressure on catalytic performance of $0.3 \% \mathrm{Pt}-4 \%$ $\mathrm{Fe} / \mathrm{AC}$ for $p$-CNB hydrogenation

\begin{tabular}{lccll}
\hline & & \multicolumn{3}{l}{ Sel./\% } \\
\cline { 3 - 5 } $\mathrm{H}_{2}$ pressure/MPa & $p$-CNB conv./\% & $p$-CAN & AN $^{a}$ & Others $^{a}$ \\
\hline 0.5 & 30 & 92.9 & n.d. & 7.1 \\
1.0 & 65 & 94.2 & n.d. & 5.8 \\
2.0 & 100 & 98.5 & n.d. & 1.5 \\
3.0 & 100 & 100 & n.d. & n.d.
\end{tabular}

${ }^{a}$ See the note in Table 1 . Other reaction conditions are the same as in Table 1.
Table 5 Reusability of $0.3 \% \mathrm{Pt}-4 \% \mathrm{Fe} / \mathrm{AC}$ catalyst for selective hydrogenation of $p-\mathrm{CNB}$

\begin{tabular}{lllll}
\hline & & \multicolumn{3}{l}{ Sel. $(\%)$} \\
\cline { 3 - 5 } Cycle number & $p$-CNB conv. (\%) & $p$-CAN & AN $^{a}$ & Others $^{a}$ \\
\hline 1 & 65 & 94.2 & n.d. & 5.8 \\
2 & 52 & 92.7 & n.d. & 7.3 \\
3 & 42 & 92.5 & n.d. & 7.5 \\
4 & 42 & 92.3 & n.d. & 7.7
\end{tabular}

${ }^{a}$ See the note in Table 1 . Reaction conditions are the same as in Table 1.

respectively. The conversion increased significantly to $100 \%$ and the selectivity reached $100 \%$ without formation of any decholorination product when the reaction temperature increased from $303 \mathrm{~K}$ to $333 \mathrm{~K}$. The byproducts produced in the reaction can be further hydrogenated to the desired product $p$ CAN. These data demonstrate that the undesired further hydrogenation of $p$-CAN can be avoided over the $0.3 \% \mathrm{Pt}-4 \% \mathrm{Fe} /$ AC catalyst in a broad window (303-333 K).
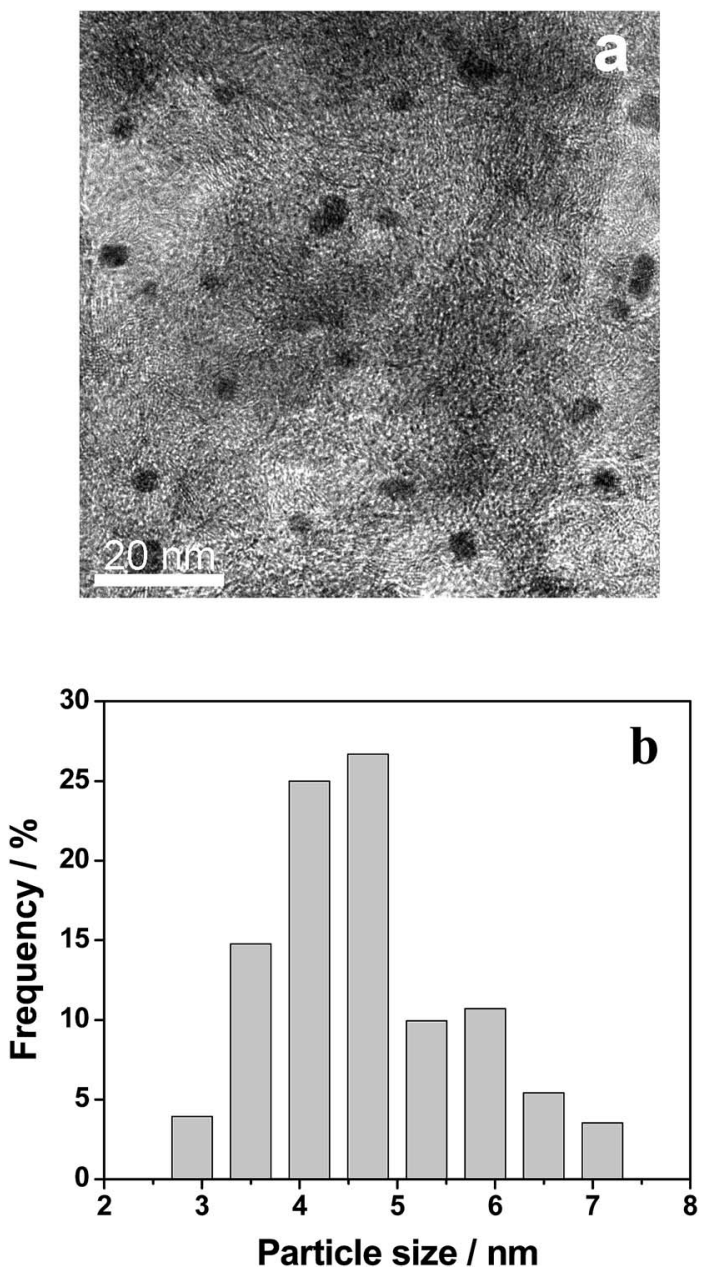

Fig. 5 TEM image of the $0.3 \% \mathrm{Pt}-4 \% \mathrm{Fe} / \mathrm{AC}$ after catalysis (a) and size distributions of $\mathrm{Pt}-\mathrm{Fe}$ particles in the catalyst (b). 
This advantage of the catalyst is clearly shown by the catalytic properties under the elevated $\mathrm{H}_{2}$ pressure (Table 4). The conversion of $p$-CNB and selectivity to $p$-CAN was $30 \%$ and $92.9 \%$ at $0.5 \mathrm{MPa} \mathrm{H}_{2}$, respectively. The conversion increased to $100 \%$ and the selectivity reached $98.5 \%$ at $2.0 \mathrm{MPa} \mathrm{H}_{2}$. It is interesting to note that any by-products derived from the hydrodechlorination were not detected, even when all of the $p$-CNB was exhausted under 3.0 $\mathrm{MPa}$, which demonstrates a remarkable feature of the $0.3 \% \mathrm{Pt}-4 \% \mathrm{Fe} / \mathrm{AC}$ catalyst for avoiding successfully any occurrence of the further hydrogenation of $p$-CAN even when very high $\mathrm{H}_{2}$ pressure is used for the reaction.

\subsection{Catalyst stability}

The recycling procedure of the $0.3 \% \mathrm{Pt}-4 \% \mathrm{Fe} / \mathrm{AC}$ catalyst was performed for examining the stability of the catalyst. The catalyst after reaction was separated by centrifugation, washed with ethanol, dried under vacuum and then reused for the same reaction. As shown in Table 5, both conversion and selectivity did not exhibit a considerable decrease for at least 4 cycles. We checked the Pt, Fe content in the recovered catalyst after 4 cycles and found that there was only a slight loss of $\mathrm{Pt}(0.02 \mathrm{wt} \%)$ and Fe $(0.35 \mathrm{wt} \%)$ in the recovered catalyst. TEM analysis showed good dispersion of $\mathrm{Pt}-\mathrm{Fe}$ particles in the recovered $0.3 \% \mathrm{Pt}-4 \%$ Fe/AC (Fig. 5a). The average Pt-Fe particle size was $4.6 \mathrm{~nm}$, with a size distribution from 3 to $7 \mathrm{~nm}$ (Fig. 5b), which is similar to that in the as-prepared fresh $0.3 \% \mathrm{Pt}-4 \% \mathrm{Fe} / \mathrm{AC}$ catalyst (4.5 $\mathrm{nm}$ ) (Fig. 2c). The as-prepared $0.3 \%$ Pt-4\% Fe/AC catalyst showed high stability.

\section{Conclusion}

In this study, we have prepared Fe modified Pt nanoparticles over activated carbon and investigated their catalytic performance on the chemoselective hydrogenation of $p$-chloronitrobenzene. It was found that the incorporation of an appropriate amount of $\mathrm{Fe}(4 \mathrm{wt} \%)$ resulted in a remarkable increase in activity, and the selectivity to $p$-chloronitrobenzene could be up to $100 \%$ at complete conversion of $p$-chloronitrobenzene over $0.3 \% \mathrm{Pt}-4 \% \mathrm{Fe} / \mathrm{AC}$ catalyst even at high temperature and $\mathrm{H}_{2}$ pressure. X-ray photoelectron spectroscopy revealed the formation of $\mathrm{Fe}_{2} \mathrm{O}_{3}$ and the electron transfer from Pt nanoparticles to $\mathrm{Fe}_{2} \mathrm{O}_{3}$, leading to the electron-deficient state of the $\mathrm{Pt}$ nanoparticles in the present catalyst, which are responsible for the improved performance of $0.3 \% \mathrm{Pt}-4 \% \mathrm{Fe} / \mathrm{AC}$ catalyst for $p$-chloronitrobenzene hydrogenation to $p$-chloroaniline. High reaction temperature and $\mathrm{H}_{2}$ pressure are favorable for $p$-CNB hydrogenation to $p$-CAN over the $0.3 \% \mathrm{Pt}-$ $4 \% \mathrm{Fe} / \mathrm{AC}$ catalyst.

\section{Acknowledgements}

This work was supported by the Science and Technology Innovation Project of Chongqing (cstc2016shmszx20004) and Project of International Science and Technology Cooperation in Chongqing (cstc2014gjhz20002).

\section{References}

1 R. S. Downing, P. J. Kunkeler and H. van Bekkum, Catal. Today, 1997, 37, 121.

2 H. U. Blaser, U. Siegrist, H. Steiner and M. Studer, in Fine Chemicals through Heterogeneous Catalysis, Wiley-VCH, Weinheim, 2001, pp. 389-406.

3 M. H. Liu, X. X. Mo, Y. Y. Liu, H. L. Xiao, Y. Zhang, J. Y. Jing, V. Colvin and W. W. Yu, Appl. Catal., A, 2012, 439-440, 192.

4 S. Ichikawa, T. Seki and T. Ikariya, Adv. Synth. Catal., 2014, 356, 2643.

5 A. B. Dongil, L. Pastor-Pérez, J. L. G. Fierro, N. Escalona and A. Sepúlveda-Escriban, Catal. Commun., 2016, 75, 55.

6 F. Cárdenas-Lizana, S. Gómez-Quero and M. A. Keane, Appl. Catal., A, 2008, 334, 199.

7 L. N. Liu, L. N. Xing, C. X. Cheng, L. X. Xia and H. Y. Liu, RSC Adv., 2016, 6, 31871.

8 Y. C. Liu, C. Y. Huang and Y. W. Chen, Ind. Eng. Chem. Res., 2006, 45, 62 .

9 Y. Y. Fan, H. L. Xiao, N. Sui, M. H. Liu and W. W. Yu, RSC Adv., 2014, 4, 11788.

10 E. Bertolucci, R. Bacsa, A. Benyounes, A. M. Raspolli-Gallett, M. R. Axet and P. Serp, ChemCatChem, 2015, 7, 2971.

11 F. Cardenas-Lizana, D. Lamey, N. Perret, S. Gomez-Quero, L. Kiwi-Minsker and M. A. Keane, Catal. Commun., 2015, 21, 46.

12 C. H. Camposa, M. Jofréa, C. C. Torresa, B. Pawelecb, J. L. G. Fierrob and P. Reyesa, Appl. Catal., A, 2014, 482, 127.

13 D. P. He, X. D. Jiao, P. Jiang, J. Wang and B. Q. Xu, Green Chem., 2012, 14, 111.

14 M. H. Liu, W. Y. Yu and H. F. Liu, J. Mol. Catal. A: Chem., 1999, 138, 295.

15 M. Makosch, W. I. Lin, V. Bumbálek, J. Sá, J. W. Medlin, K. Hungerbühler and J. A. van Bokhoven, ACS Catal., 2012, 2, 2079.

16 S. Furukawa, Y. Yoshida and T. Komatsu, ACS Catal., 2014, 4, 1441.

17 K. Möbus, D. Wolf, H. Benischke, U. Dittmeier, K. Simon, U. Packruhn, R. Jantke, S. Weidlich, C. Weber and B. S. Chen, Top. Catal., 2010, 53, 1126.

18 N. Mahata, O. S. G. P. Soaresa, I. Rodríguez-Ramos, M. F. R. Pereira, J. J. M. Órfão and J. L. Figueiredo, Appl. Catal., A, 2013, 464-465, 28.

19 H. Zhu, W. F. Han, H. F. Chai and H. Z. Liu, Chin. J. Catal., 2007, 28, 196.

20 P. R. Shukla, S. B. Wang, H. Q. Sun, H. M. Ang and M. Tadé, Appl. Catal., B, 2010, 100, 529.

21 A. Shukla, R. K. Singha, T. Sasaki and R. Bal, Green Chem., 2015, 17, 785.

22 W. J. Li, L. M. Ye, P. Long, J. Chen, H. Ariga, K. Asakurab and Y. Z. Yuan, RSC Adv., 2014, 4, 29072.

23 J. Gong, K. Yao, J. Liu, Z. W. Jiang, X. C. Chen, X. Wen, E. Mijowska, N. N. Tian and T. Tang, J. Mater. Chem. A, 2013, 1, 5247.

24 L. Olsson and E. Fridell, J. Catal., 2002, 210, 340. 
25 J. L. Zhang, Y. Wang, H. Ji, Y. G. Wei, N. Z. Wu, B. J. Zuo and Q. L. Wang, J. Catal., 2005, 229, 114.

26 X. X. Han, R. X. Zhou, G. H. Lai and X. M. Zheng, Catal. Today, 2004, 93-95, 433.

27 C. Lian, H. Q. Liu, C. Xiao, W. Yang, K. Zhang, Y. Liu and Y. Wang, Chem. Commun., 2012, 48, 3124.
28 H. M. Liu, H. B. Yu, C. R. Xiong and S. H. Zhou, RSC Adv., 2015, 5, 20238.

29 C. S. Lu, M. J. Wang, Z. L. Feng, Y. N. Qi, F. Feng, L. Ma, Q. F. Zhang and X. N. Li, Catal. Sci. Technol., 2017, 7, 1581. 